\title{
IDENTIDADES, NO IDENTIDADES Y POSTIDENTIDADES EN HOMBRES BIOLÓGICOS LATINOS QUE SE CONSTRUYEN EN LAS FEMINIDADES
}

\author{
Manuel Antonio Velandia Mora \\ Universidad Cooperativa de Colombia \\ (Sede Bogotá) \\ Universidad de Alicante \\ España
}

Recibido/12/03/2012

Aceptado/24/05/2012

\section{Resumen}

Las personas que han transitado hacia las feminidades son ubicadas cultural, política, económica y socialmente en una categoría inferior que las mujeres y los homosexuales, por ello son víctimas de toda clase de crímenes de odio perpetrados, incluso por las personas transitadas a las masculinidades; su experiencia es la más queer de todas porque han transgredido el «deber ser» de los modelos de sexo, cuerpo, genero, orientación sexual y expresiones comportamentales sexuales y lo han hecho hacia un sexo y un género marcado por la otredad y el entendimiento binario de la realidad social jerarquizada, situación aún más grave para las «inmigrantes». El estudio sobre cómo construyen las identidades transitadas contribuye al desarrollo de las políticas sexuales de todas las minorías, pero dicho estudio debe hacerse desde otras epistemologías y ontologías, aquí se aborda desde la teoría de sistemas y las ontologías constitutivas.

Palabras clave: Transito identitario de género, Identidad de género, Travesti, Femenino, Teoría de sistemas. 


\begin{abstract}
People who have transited to femininities are located culturally, politically, economically and socially in a lower category than women and homosexuals, so they are victims of all kinds of hate crimes perpetrated by everybody, even by people who transited to masculinity; their experience is the queerest of all because they have transgressed the «should be» models of sex, body, gender, sexual orientation and sexual behavioral expressions and have done to a sex and a genre marked by otherness and the binary understanding of the social hierarchy, a situation even worse for «immigrants». The study of how they construct their transited identities contributes to the development of the sexual politics of all minorities, but that study should be done from other epistemologies and ontologies, here is approached from systems theory and the constitutive ontology of the observer.
\end{abstract}

Key words: travel of gender identity, gender identity, Travesti, Feminine, System theor 
El primer antagonismo de clases que apareció en la historia coincide con el desarrollo del antagonismo entre el hombre y la mujer en la monogamia; y la primera opresión de clases, con la del sexo femenino por el masculino.

Engels, 1884

El Origen de la familia, la propiedad privada y el estado

Este artículo se basa en una investigación longitudinal en proceso, que como propone Halberstam, se apoya en una metodología queer que en cierto sentido resalta la importancia de mirar a las subculturas, entendiendo éstas como aquellas minorías culturales dentro de una cultura más homogénea, y les dedica un espacio en la investigación en tanto que conforman parte esencial del objeto de estudio. No sigo un patrón académico tradicional, aun cuando el estudio puede enmarcarse como cualitativo etnográfico. Se apoya en entrevistas, grupos de discusión y observación, pero fractura los parámetros tradicionales de la observación participante porque utilizo la reflexividad, que como afirma Bourdieu, rompe con el modelo tradicional al asumir una posición no vertical al construir el «objeto» de investigación, al entender que la reflexividad es:

El papel activo del «sujeto» en la construcción del «objeto», la relación subjetiva, personal, intima del «sujeto» con el «objeto», la posición del «sujeto» en un campo o sub-campo específico de la producción cultural y el lugar que ocupa dicho campo o sub-campo en la estructura del espacio social y en las relaciones con otros campos más o menos dominantes. De tal modo, el «objeto» se expande, pues el «sujeto» se hace también «objeto» de la observación ${ }^{1}$.

En mi interés investigativo me alejo de la objetividad, para aproximarme desde las ontologías de la constitutividad, negándome así la posibilidad de hacer del mundo social un «espectáculo» susceptible al análisis científico al obviar la distinción tajante entre sujeto y objeto, entre observador y observado.

Es más, en ese ejercicio constitutivo por momentos algunas de los interlocutores me asumieron en femenino, me trataron en femenino e incluso participé de sus ritos de maquillaje y vestido como una manera de profundizar

1. Bourdieu, Pierre. El Sentido Práctico, Buenos Aires, Siglo XXI, (1980) 2007, p. 53.

Feminismo/s 19, junio 2012, pp. 185-209 
en mi propia identidad ${ }^{2}$. En lo personal no trabajo con informantes, sino con interlocutores pertenecientes a las minorías sexuales que interrogo. Interlocutores es como propone llamarlos Cardoso De Oliveira buscando un diálogo intercultural que supere las relaciones de poder involucradas ${ }^{3}$. No se trata sólo de proponer un nuevo término para un viejo estilo de recolección de información, sino de estipular claramente e inaugurar un diferente tipo de relación social con las personas con las que nos vinculamos ${ }^{4}$.

Cuando inicié las entrevistas pensé en tener como fuentes a hombres/ homo/femeninos/trabajadores sexuales, sin embargo, en el transcurso de las acciones llevadas a cabo para recolectar los datos observé que los interlocutores no solo rompían con la causalidad aparentemente natural que enlaza cuerpo, sexo, género, orientación sexual y el uso y nominación de los genitales y el ano en su posibilidad placentera, sino que además no se concebían como hombres femeninos y si como mujeres o como personas femeninas e igualmente, algunos pasaron de pensarse homosexuales a asumirse heterosexuales.

El concepto trans que se utiliza en este texto es el propuesto por GATE $^{5}$ que se usa para describir a aquellas personas que transgreden el binarismo normativo del género, lo que conlleva la experiencia de enfrentarse a problemas de derechos humanos como resultado. Para GATE en las personas trans se incluye a aquellas que tienen una identidad de género, que es diferente a la del género asignado al nacer y / o aquellas personas que sienten, que tienen que, o prefieren elegir la ropa, accesorios, cosméticos o modificaciones del cuerpo que presentan diferencias con las expectativas de los roles de género asignados a ellos en el nacimiento. El término, entre muchos otros, incluye a las personas transexuales y transgéneros, travestis, cross dressers, no géneros y a los genderqueer people.

Los temas propuestos en las entrevistas y grupos de discusión han sido de especial interés para todas las entrevistadas y aparecían de manera

2. Santander, ubicado en la zona nororiental del país, es una zona tradicionalmente machista de Colombia.

3. Cardoso Deoliveira, Roberto. O trabalho do antropólogo. São Paulo, Paralelo 15 y Editora Universidade Estadual Paulista. 1998.

4. BARTOlOmÉ, Miguel Alberto. En defensa de la etnografía. El Papel contemporáneo de la investigación intercultural, Revista de Antropología Social, diciembre de 2003, pp. 199222. Disponible en: http://www.ucm.es/BUCM/revistas/cps/1131558x/articulos/ RASO0303110199A.PDF

5. GATE: Global Action for Trans Equality (Acción Global para la Igualdad Trans) es una organización internacional que trabaja por los derechos humanos de las personas trans. GATE produce conocimiento crítico y hace disponibles recursos para activistas trans; apoya a los movimientos trans en todo el mundo; y, trabaja por los derechos trans a nivel internacional. 
recurrente y espontánea en sus reflexiones cotidianas. Algunas de las entrevistadas manifestaron haberse sentido muy a gusto durante la actividad y afirmaron haber encontrado un espacio de reflexión y de comunicación; incluso para otras, el encuentro representó un espacio terapéutico, donde pudieron expresar libremente importantes elementos relacionados con sus procesos existenciales. Ninguna ha terminado el bachillerato, todas tienen algún grado de educación primaria (...). No se sienten a gusto en un baño de hombres y tienen gran temor de entrar a un baño de mujeres, detestan orinar de pie cuando están en femenino y casi todas odian que las traten en masculino estando en femenino.

Todas, las entrevistadas, han ejercido el trabajo sexual, todas lo han hecho en la calle. Todas son autónomas (no tienen un jefe) y la mayoría han sido víctimas de maltrato por parte de sus clientes, de sus parejas «permanentes»... Todas fueron maltratadas en razón del tránsito identitario por miembros de su familia, incluyendo además de padres y madres a hermanos y otros parientes cercanos.

\section{Una aproximación a las vivencias de las neo-féminas y las neo-mujeres.}

Las trans interlocutoras nunca se propusieron ser queer, resultaron así, la vida las fue llevando por esos caminos contraculturales en las que primo su «querer ser» frente al «deber ser».

Desde la teoría, desde la práctica y desde sus propias emociones han construido aproximaciones discursivas y vivenciales sobre la construcción del cuerpo, el sexo y el género. En su ejercicio de vida en tránsito han tenido sus más profundas discusiones existenciales y las han resuelto de muy diversas maneras, aun cuando se evidencia que en sus vivencias y explicaciones hay elementos comunes.

No hay en ellas una unidad de discurso, se trata más bien de una narrativa del «sí mismo», de cómo han vivido, el cuerpo, el sexo, el género, la genitalidad, pero igualmente es una narrativa en la que las reflexiones se ven afectadas por el «otro», por esas otras personas con las que se interactúa en los grupos de discusión. Por consiguiente se puede afirmar que el suyo es un discurso situado pero no un discurso académico o propio de la teoría feminista. «Cada una construye un momento narrativo específico cuando su identificación sexual personal pasa de masculina a femenina $»^{6}$.

6. STONE, Sandy. «El imperio contraataca: Un manifiesto postransexual», en: Serias para el debate. No. 3, Lima, Campaña por la convención de los derechos sexuales y los derechos reproductivos, (1991) 2004, pp. 13-32. 
En algún momento de mi vida sentí que la historia que podía contar de mí precisaba de un cambio en la posición enunciativa, que no tenía que ver con hacer más verdadero el relato, más aproximado a lo que soy, sino con el placer de pronunciar palabras desde cierto lugar, de experimentar la contradicción entre mi nombre y mi apariencia, explorar otros modos de la masculinidad, ser llamado de otro modo ${ }^{7}$.

No se caracterizan por ser políticamente correctas; se han visto obligadas a transgredir las normas establecidas del «deber ser» para resolver la economía de lo cotidiano y como algunas de ellas dicen con relación a su estatus legal de permanencia en España, son «ilegales» ${ }^{8}$.

Las interlocutoras se encuentran en distintas fases de su proceso de intervención del cuerpo y de construcción de una identidad femenina.

En su infancia, no se caracterizaron por ser unos «machitos» y en la escuela, en el barrio o en la casa les hicieron dar cuenta de que «algo andaba mal». Ninguna jugó al futbol, evitaron los juegos «bruscos» y se caracterizaron porque sus compañeros de juego eran igualmente «poco machos» y en su mayoría niñas. Fueron sorprendidos, maltratados y excluidos por jugar con muñecas, prefirieron en los juegos el rol de «mamá», aun cuando no se distinguieron por apoyar a las madres en las labores cotidianas del hogar.

El momento culminante que dio pie a su tránsito lo ubican entre los 13 y los 15 años y lo relacionan con un momento en el que -a pesar de las contradicciones, regaños, violencias, exclusiones, separaciones- pueden recordar como un momento feliz. No saben muy bien cuándo comenzaron su tránsito, algunas recuerdan episodios a edades muy tempranas, incluso a los cinco o seis años. Lo que sí tienen claro es ese momento en que «algo paso, una transgresión que provocó una ruptura familiar» o como mínimo fueron objeto de una violencia física o emocional por parte de un familiar.

Ninguna buscó apoyo emocional y todas encontraron en algún momento una persona cómplice con quien compartir sus dudas, hallazgos, emociones, experiencias, explicaciones, experimentos hormonales; las más jóvenes buscaron información en Internet. Y todas tuvieron un modelo femenino a quien durante mucho tiempo imitaron, tradicionalmente una actriz conocida y nunca alguien de la familia.

7. BIMBI, Bruno. Entrevista a Mauro Cabral. Los medios hablan de nosotros como personas que necesariamente sufren, en: Revista Imperio G. 6/06/2006. Disponible en: http:/ /bbimbi. blogspot.com/2006/06/revista-imperio-g-entrevista-mauro.html

8. Término peyorativo con el que se designa a un ciudadano extranjero que se encuentra en territorio español sin la documentación necesaria, prevista en las leyes. Correctamente habría de referirse a este como indocumentado o sin papeles. 
Experimentaron miedo antes de decidirlo públicamente, de hacerlo permanentemente y de salir a la calle en femenino; no se negaron la oportunidad de «vestirse» en múltiples ocasiones. Actualmente el vestido femenino es un hecho asumido que no les causa conflicto, así lo hagan únicamente por algunos momentos, momentos que se pueden extender por días, meses o años. «Con relación a mi vestido, para decirlo de alguna manera, por momentos soy cross-dressers (quienes ocasionalmente usan atuendos social, cultural y políticamente reconocidos como del sexo opuesto), no soy drag queens tampoco transformista ni travesti, solo me visto femenina para ser puta ${ }^{9}$.

Recuerdan con gran interés el primer momento en que entraron en una tienda para comprar ropa femenina. Un momento determinante en su proceso identitario es aquel en que se decidieron a usar lencería femenina; se ven a sí mismas más atractivas vistiendo en femenino. Todas involucran intervenciones y transformaciones en el cuerpo, pero es necesario aclarar que a lo largo del tiempo y del espacio existen diversas experiencias de tránsitos en los géneros que no necesariamente implican una intervención hormonal y quirúrgica. Sin excepción han recibido «terapia hormonal» auto-medicada, lo que algunos teóricos llaman intervenciones «artesanales»; es decir, consumen hormonas sin ningún tipo de acompañamiento médico.

Estas pastillas producen en las mujeres biológicas un efecto anovulatorio $y$ en las mujeres transexuales un efecto feminizante. $Y$ en ambos casos embellecen la piel, hacen crecer los senos, disminuyen el bello corporal, generan depresiones y «feminizan» el deseo sexual ${ }^{10}$.

No conocen los componentes químicos de los fármacos, se guían por las alteraciones corporales que van experimentando, alterando la combinación de fármacos mediante series de ensayo-error, aconsejando la que menos errores haya ocasionado y mejores resultados en menos tiempo y con más usuarias. Los riesgos en el sistema cardiovascular y el metabolismo en general de ingerir anticonceptivos como «esteroides sexuales» (afirman que son estrógenos que frenan la creación de testosterona) son temas que no entran dentro del ámbito sociológico por la especialización del tema ${ }^{11}$.

9. Myriam, 32 años, Chilena.

10. GARCía BECERRA, Andrea. Tacones, siliconas, hormonas. Teoría feminista y experiencias trans en Bogotá, Bogotá, Universidad Nacional de Colombia, Facultad de Ciencias Humanas, Escuela de Estudios de Género, 2010

11. AMARO QUINTAS. Ángel Manuel. Triplemente vulnerabilizadas. Prostitutas, inmigrantes y transexuales Vulnerabilidad en la salud, servicios de salud y contexto/s, Alicante, Instituto Universitario de Desarrollo Social y Paz, 2010. Disponible en http://www.transexualia. org/DOCUMENTACION/triplemente.pdf 
Yo tengo entendido que al tomar hormonas, la hormona femenina para la mujer es para frenarle la regla. Y para nosotras, como no somos mujeres, como no tenemos menstruación, se convierte en femenina, lo que tengo entendido, ataca a la masculina. (Marina, 27 años, ecuatoriana)

Nos guiamos por la experiencia. Yo te digo tómate Dramipijona o primogin, tu comienzas a tomar una o dos diarias y ya está, han pasado dos o tres semanas y te digo ven a ver si tienes piedra, piedra es cuando se te pone el pezón duro, empieza a crecer, y se te agrandan los senos, poco a poco irás viendo que se te va haciendo busto y se te van haciendo tetas. (Marina, 27 años, ecuatoriana)

Una amiga mía estuvo esperando 6 meses para que el endocrino le diga que hormona tiene que tomarse, la otra comenzó igualito que ella y a los 6 meses vino de Ecuador montada, puesta tetas, puesta todo, guapísima, mujerona y se harta a trabajar, y sin una gota de hormonas. Está lindísima. (Ana, 47 años, ecuatoriana)

Me niego a aceptar que tengo una enfermedad denominada disforia de género; si he seguido el juego al equipo médico es porque esta es la única manera en que puedo tener la transformación del cuerpo que deseo y hacerlo disminuyendo los riesgos para mi vida (...) lo hago porque sé por lo que han pasado otras que se lo han hecho por sí mismas y sin ayuda profesional. (...) La teoría dice que como mínimo se deben seguir dos años a terapia psicológica y terapia psiquiátrica, yo los acepté pero sé que no soy ninguna enferma mental, que no estoy «loca»... por lo menos no de la cabeza (...). Obviamente todos esperan que yo acepte la «cirugía de reasignación de sexo» pero no es mi interés hacérmela, no por ahora, esto de la identidad es tan cambiante que no sé si más adelante pensaré otra cosa». (Sofia, 24 años, argentino/española)

En estas experiencias de vida se observa que las feminidades dependen de la posición y subjetivización de quien la construye.

Yo no soy transexual, yo no pienso en femenino, mi pensamiento tiene muchos rezagos de la masculinidad heteronormativa y algunos elementos de esa feminidad tradicional como también de lo que yo creo es la feminidad que yo asumo, yo no me quiero cambiar de sexo... no quiero tener unas grandes tetas... me gusta mi pecho, el pecho con el que nací; me gusta mi pene y no quiero perderlo, pero no ejerzo la falocracia; por eso diga que no soy transexual, tampoco soy travesti simplemente soy ese ser único que quiero ser. No soy ese otro o esa otra que los demás ven o no quieren ver; esa identidad no es la mía, es la que ellos me asignan desde su manera de entender la sexualidad. (Vanessa, 23 años, argentina)

Ser mujer, femenina y lesbiana no es un continuo lineal, algunas mujeres transitadas que ya se han practicado la cirugía de reasignación de sexo, no se identifican transexuales sino mujeres.

Hay veces que me arrepiento de haberme operado, no me arrepiento de ser mujer, lo volvería hacer 100.000 veces más. Pero, hay veces que dices, coño, 
para qué me corté la verga. Me dicen, cuánto cobras, 30, ¿la tienes grande? Les digo que soy mujer y se van. (Ana, 47 años, ecuatoriana)

Cuando estoy con un tío que es más marica que yo, más mujer que yo, me convierto en una mujer macha, me pongo dominante... no me gusta sentirme lesbiana, pero si se es puta terminamos haciendo por dinero lo que no nos gusta, lo que incluso odiamos. Cuando estoy junto a esos hombres mariquitas me siento homosexual, me molesta que sean tan mujeres y digan que son hombres, yo los trato como mujeres y a algunos les molesta pero a la mayoría no, yo de esas maricas soy amiga, pero no follaría, no soy lesbiana. (...) tampoco me aguanto a las que dicen que son tías y son más machas que cualquier hombre, con esas voces todas gruesas, esas manos tan grandes y esos ademanes de macho espantan a los clientes, los asustan, ellos nos quieren femeninas. (Ana, 47 años, ecuatoriana)

Yo recuerdo que mi madre me decía que me portara como un hombre y yo le pregunté cómo se portaban los hombres, ella me respondió que un hombre de verdad nunca se portaría como una mujer, que un hombre sabe que no es una mujer. Ahora me da risa esa respuesta porque, según ella lo afirmaba, yo ahora soy un hombre porque sé que no soy una mujer... Pero también tengo claro que no soy un hombre simplemente porque no es lo que yo quiero ser, quiero decir que ser hombre o ser mujer o dejar de ser hombre o mujer, o ser masculino o femenino o dejar de serlo es una decisión personal que algunos nunca piensan porque no se permiten dudar de esos modelos otras en cambio nos permitimos pensarlo, nos permitimos negarlo, nos permitimos dejar de serlo para ser lo que queremos ser, en ese sentido la decisión es una opción diaria porque aun con estas tetas, que no son mías porque yo las asumo como un accesorio más, yo puedo ser un Ser masculino. (Guipsy, 28 años, uruguaya)

En algún momento se han pensado homosexuales, algunas se asumen en sus relaciones con sus parejas como heterosexuales. (...) podemos ser completamente revolucionarias en lo público pero absolutamente sumisas en lo privado. Afuera, mujeres trans feministas. Adentro, hembritas trans tradicionales y subordinadas a los deseos del macho. (...) Jamás se harían la cirugía de cambio de sexo pues disfrutan teniendo un pene y usándolo para penetrar hombres. Sin embargo, poseer un pene y usarlo para penetrar a los hombres no cuestiona en lo más mínimo su identidad femenina y hetero ${ }^{12}$.

No soy homosexual, no soy lesbiana, no soy bisexual pero mucho menos soy heterosexual; soy un ser que ama a hombres y a mujeres, biológicos o construidos, tengo experiencias eróticas y genitales con ellos y ellas, en las que la relación se plantea de manera particular con cada uno, sin ponerle un rótulo. No es mi necesidad rotularme, esa es una necesidad social que hace que los seres humanos anden clasificando como una manera de entender y explicar el mundo en un esquema lineal en la que si tienes pene debes ser masculino,

12. Ibíd., p 80

Feminismo/s 19, junio 2012, pp. 185-209 
heterosexual, falocrático, machista y misógino. Yo tengo pene pero me resisto a seguir esa línea, he roto con la masculinidad, la heterosexualidad, la falocracia, el machismo y la misoginia para ser yo mismo; el pene no es mi esencia, mi pene es un elemento más del cuerpo con el que se obtiene y produce placer como con cualquier otro milímetro de la extensión de mi cuerpo. (Vanessa, 23 años, argentina)

Yo soy lesbiana, aun cuando tengo relaciones con hombres eso es trabajo, a mí lo que me gustan son las mujeres. Ahora mismo tengo una pareja, ella es lesbiana también, pero es mujer biológica. No tenemos relaciones penetrativas entre nosotras, en esto se diferencian las relaciones de amor de las de trabajo. Ella me conoció femenina y le gustan de mí aquellos pequeños rezagos masculinos que me quedan. Cuando estamos juntas el pene es un estorbo, pero yo sé que lo necesito para comer, porque de mi pene también vive mi familia; por eso no me lo quito... bueno nunca he pensado en quitármelo, tengo claro que soy una lesbiana con un clítoris muy grande. (Raquel, 29 años, colombiana)

Existen también sexualidades trans lesbianas. Muchas personas después de realizar su tránsito a lo femenino, después de la transformación corporal y de la cirugía de reasignación de sexo, se reconocen como lesbianas, como mujeres transexuales lesbianas, sus deseos van dirigidos a las mujeres y sus prácticas sexuales solo se desarrollan con otras mujeres. Algunas personas transexuales estaban casadas cuando eran hombres y mantienen estas relaciones después del tránsito (relaciones amorosas, maritales, incluso, paternales, con hijos e hijas). Ellas tienden a reconocerse como lesbianas sin muchos inconvenientes, pero sería interesante preguntarse cómo sienten estas experiencias sus parejas mujeres, primero relacionadas amorosa, afectiva y sexualmente con un hombre, ahora, con una mujer trans. Seguramente esto implica muchas reelaboraciones de las categorías de sexualidad tradicionales -heterosexualidad, homosexualidad, lesbianismo- por parte de las parejas de las trans ${ }^{13}$.

Para ellas «Ser trans» no representa una condición estable, inmutable, constante, sino que es un proceso de construcción, un proceso que se abandona por momentos, que se retoma por otros tiempos pero que siempre está en continuo crecimiento. Ninguna ha pensado dejar de transitar, aun cuando alguna de ellas reconoce que «en el futuro, cuando sea calva, porque el pelo se me cae a manotadas, dejaré de vestirme en femenino, pero seguiré siendo femenina, una «loca femenina» pero igual de marica que ahora» ${ }^{14}$.

Algunas trans no son extremadamente femeninas, incluso parecen señoras amas de casa poco preocupadas por su cuerpo, por lo que se ponen o por su maquillaje y peinado. Esas trans pasan desapercibidas, no las piensan trans; yo en cambio no quiero ser mujer, valoro esa diferencia que me separa del

13. Ibíd., p. 81

14. Michel, 33 años, peruana 
resto de seres en la sociedad, esa diferencia que me hace distinta y única, una diferencia que yo he construido, que he pulido con el paso del tiempo. Una diferencia que es una agresión a una sociedad que no acepta que los seres humanos tenemos el derecho a ser lo que queremos ser y que nos vulnera porque considera que tenemos que ser como debe ser, pero esto no es claro qué es ese deber ser. (Margarita, 31 años, venezolana)

El cuerpo sea biológico o construido no es la cárcel de la masculinidad o la feminidad, es un accesorio que yo transformo a mi antojo. Yo digo que «soy una chica con antena al piso», es decir que la «antena» es una cosa que está ahí pero que no me define, en cambio tener la «vagina atrás», en lo que para otros es el culo, es una decisión particular, yo soy quien la contempla como vagina, yo me hago mi propia vagina y para mi pareja yo soy una mujer a quien penetra no en una relación homosexual sino en una relación heterosexual porque para él yo soy su mujer, es decir él también me construye en la palabra, el me hace mujer y me hace heterosexual, así yo me piense homosexual y a él lo piense eso que ahora llaman un hombre que tiene sexo con otros hombres, porque así es como a él lo definen los que trabajan en prevención del sida. Fíjese que la identidad es una construcción, porque yo me construyo, mi pareja me construye y los que hacen la prevención lo construyen a él y a mí. Eso quiere decir que todos somos construcciones y que cuada cual construye al otro desde sus propios parámetros. (Devora Dora, 33 años, colombiana)

Quisieran tener un documento de identidad femenino, este posicionamiento en lo femenino no implica una identidad como mujer en términos exclusivos. Algunas consideran que el documento no debería informar del sexo.

Mi identidad es una no identidad. Yo no soy esa que dice el documento de identidad, porque me identidad no es la legal, la que me ha sido atribuida, en la que me han asignado, sino la que yo he construido para mí. Tampoco he dejado de ser esa otra, ese otro, el del documento de identidad, el que los padres formaron o más correctamente deformaron porque en mi hay de ambas identidades, pero actualmente hay mucho más de la fémina que quiero ser. Soy fémina, no mujer; no me interesa ser mujer, solo me interesa ser femenina. (Beatriz, 29 años, ecuatoriana)

\section{Identidades transitadas}

Los cuerpos no alineados son leídos en clave de síndromes. Las identidades responden a una serie de procesos históricos, sociales, culturales y políticos que las configuran, posibilitando su construcción, implicando procesos de fractura y reconfiguración, generando espacios de expresión y contextos de luchas donde se manifiestan las fuerzas, las debilidades, las imágenes y los discursos de las identidades. «Soy una persona trans, alguien que fue atribuido 
al sexo masculino y se identifica según el momento en el género femenino, en el masculino o simplemente no se identifica» ${ }^{15}$.

Transgéneros, travestis y transexuales son transgresores en la medida en que hacen una ruptura con la bipolaridad masculina/femenina. Quienes transitan a la feminidad, en la búsqueda de ser femeninas exacerban su propia feminidad, por lo que podríamos hablar aquí de hiperidentidades. La hiperfeminidad se caracteriza por la exageración de lo que se considera como «lo femenino», tanto en el cuerpo como en el comportamiento.

La identidad femenina que ellas viven puede entenderse como un proceso postidentitario porque se permite vivir de la feminidad, no entendida socialmente, sino lo que cada una de ellas particularmente asume, su «querer estar siendo» femenina.

Los seres humanos tenemos la necesidad de construir una subjetividad pública y reconocible.

Las trans construyen sus cuerpos, sus identidades y sus formas de sociabilidad, evidenciando sus pequeñas luchas cotidianas, sus intensas negociaciones encarnadas y las sutiles transformaciones que, mediante sus experiencias, realizan en los mundos que habitan ${ }^{16}$.

Para Preciado este hecho ilustra como los dispositivos institucionales de poder de la modernidad (desde la medicina al sistema educativo, pasando por las instituciones jurídicas o la industria cultural) han trabajado unánimemente en la construcción de un régimen específico de construcción de la diferencia sexual y de género. Un régimen en el que la normalidad (lo natural) estaría representado por lo masculino y lo femenino, mientras otras identidades sexuales (transgéneros, transexuales, discapacitados,...) no serían más que la excepción, el error o el fallo, monstruoso que confirma la regla ${ }^{17}$.

El poder actúa a través de una molécula que viene a formar parte de nuestro sistema inmunitario, de la silicona que toma la forma de senos, de un neurotransmisor que modifica nuestra forma de percibir y actuar, de una hormona y su acción sistémica sobre el hambre, el sueño, la excitación sexual, la agresividad o la descodificación social de nuestra masculinidad y nuestra feminidad ${ }^{18}$.

Desde la experiencia de cuerpo de algunas neo-mujeres y neo-féminas -una experiencia cotidiana que en muy contadas ocasiones está marcada por la

15. Guipsy, 28 años, uruguaya

16. GARCÍA BECERRA, Op. cit., p 10

17. Preciado, Beatriz; Halberstan, Judith; BourCier, Marie-Hélène. Retóricas del género/ Políticas de identidad: performance, performatividad y prótesis. Resumen de las sesiones de trabajo. Disponible en: http://www.caladona.org/grups/uploads/2011/02/retoricasde-genero-politicas-de-identidad-b-preciado.pdf

18. PRECIADO, Beatriz. 2008. Testo yonki. Espasa. Madrid. 
teoría y la política- se cuestionan las categorías hegemónicas, binarias y naturalizadas de hombre y mujer.

Afirma García Becerra que algunos teóricos como Fausto-Sterling en 2006, consideran que las diferencias entre lo masculino y lo femenino pertenecen a la naturaleza humana. El orden binario de los sexos aparece con dimorfismo radical, de divergencia biológica. «De este modo, la segmentación jerárquica masculino-femenino se implanta rígidamente, mediante la naturalización arbitraria de una estructura binaria-simbólica, de género-que organiza el cosmos, el mundo social, las cosas y los cuerpos» ${ }^{19}$.

El viejo modelo, en el que hombres y mujeres se ordenaban según su grado de perfección metafísica, su calor vital, a lo largo de un eje de carácter masculino, dio paso a finales del siglo XVIII a un nuevo modelo de dimorfismo radical, de divergencia biológica. Una anatomía y una fisiología de lo inconmensurable sustituyo a una metafísica de la jerarquía en la representación de la mujer en relación con el hombre ${ }^{20}$.

De este modo, la segmentación jerárquica masculino-femenino se implanta rígidamente, mediante la naturalización arbitraria de una estructura binaria -simbólica, de género- que organiza el cosmos, el mundo social, las cosas y los cuerpos ${ }^{21}$.

Las trans estamos en fuga, en tanto no nos identificamos con la categoría «hombres», cuestionamos una masculinidad que se ha querido implantar en nuestros cuerpos y desnaturalizamos de algún modo los órdenes de género: sin haber nacido mujeres, la feminidad es lo que nos constituye y es aquello por lo que nos exponemos a múltiples violencias y discriminaciones (...). La gran mayoría de trans, travestis o transexuales rechazamos enérgicamente la categoría de «hombres» y no nos reconocemos en lo masculino: haber sido alguna vez hombres o haber estado ubicadas en lo masculino, en nuestro caso, es algo que duele, que nos hiere profundamente y no es una forma de identidad deseable ${ }^{22}$.

Por otra parte cabe resaltar que la reproducción social de la masculinidad tradicional es un caldo de cultivo para conductas contrarias a la igualdad, como el machismo, la misoginia, la violencia de género y la LGTBIfobia ${ }^{23}$.

«No se nace mujer: se llega a serlo» (De Beauvoir, 1949: 207). Idea matizada por Judith Butler quien considera que se «llega a ser» mujer, bajo la

19. GARCía BeCERRA, Op. cit., p 32

20. Laqueur, Thomas. La Construcción del Sexo. Cuerpo y género desde los griegos hasta Freud, Madrid, Cátedra, (1990) 1994.

21. Bourdieu, Pierre. La Dominación Masculina, Barcelona, Anagrama (1998) 2000..

22. GARCÍA BECERRA, Op. cit., p. 67

23. Aguiló, Antoni Jesús. Diversidad sexual y derechos humanos: cinco desafíos de nuestro tiempo, en Papers de l'ateneu. Número 19, enero 2012. Disponible en: http://ateneuperemascaro.org/documentacio/informes/papers-de-l-ateneu-numero-1.html 
obligación cultural de serlo. El transito trans hacia un* otr* adquiriendo elementos considerados propios de la feminidad o la masculinidad es una transgresión del binarismo sexual. Las personas que transitan en el cuerpo, en el sexo y en el género pasan por un proceso de «liberación gradual del género y sus restricciones binarias» (Butler, 1982). Por lo que podría afirmarse con Butler que estas personas construyen su propia «performatividad de género», como también su propia performatividad de cuerpo y sexo; por lo que podría ratificarse que las suyas no son construcciones «artificiales» o «desviadas», sino una de las múltiples posibilidades en el ejercicio performativo, siendo éstas construcciones coherentes con el proceso de construcción identitaria ${ }^{24}$.

Algunas de ellas se identifican en una neo-feminidad y como neomujeres pero otras se aproximan al sueño que a Rubin le parece más atractivo, «el de una sociedad andrógina y sin género, en el que la anatomía sexual no tenga ninguna importancia para lo que uno es, lo que hace y con quien hace el amor» ${ }^{25}$.

Vivencian postidentidades aunque no se lo proponen como meta. Las neo feminidades no son una copia de lo que social, territorial, cultural y políticamente se identifica con la feminidad sino que son hiperidentidades, pues quienes transitan a la feminidad, en la medida que quieren ser femeninas, exacerban su propia feminidad.

El matrimonio heterosexual, cual extensión de las formas de producción, ubica a las mujeres en un patrón de dominación/dependencia que se extiende al matrimonio y las relaciones de pareja de las personas transitadas neo-féminas y neo-mujeres. Son igualmente esclavizadas sexualmente por sus parejas y en muchos de los casos sus parejas-chulos-maridos las ofertan en el mercado sexual como objetos consumibles y utilizables por otros hombres, quienes en su mayoría y de igual forma pasan por procesos de auto-negación identitaria con relación a su identidad de orientación sexual, homofobia ${ }^{26}$ internaliza$\mathrm{da}^{27}$ que igualmente actúa como acicate en la vulneración a las neo-féminas y neo-mujeres.

Cabe destacar que en las neo-féminas y las neo-mujeres el sexo no es el sustrato biológico, natural $\mathrm{u}$ objetivo que algunos autores como Mara

24. García BeCERra, Op. cit., p. 33

25. RuBin, Gayle. «El tráfico de mujeres: Notas sobre la «economía política» del sexo», en: El género: La construcción cultural de la diferencia sexual. Marta Lamas (comp.), México, PUEG - UNAM, (1975) 1996. pp. 35-96.

26. La homofobia es el conjunto de creencias, prácticas y normas que expresan miedo irracional y odio hacia las personas que prefieren las relaciones sexuales y amorosas con seres de su propio género.

27. La homofobia internalizada es la homofobia que incorporan a su psique y sus comportamientos aquellos hombres que no aceptan su preferencia deseante, erótica, afectiva y genital hacia otros hombres biológicos o construidos. 
Viveros ven en las mujeres, al considerar que «El mecanismo de producción de la diferencia opera por naturalización, deshistorización, universalización y biologización $»^{28}$. Pero no por ello dejan de ser consideradas mujeres y excluidas como tales.

\section{Del trabajo sexual}

El trabajo sexual se ha entendido como una categoría relativa a la mujer y en consecuencia neo-féminas y neo-mujeres que lo ejercen son víctimas de las opresiones y vulneraciones de las que tradicionalmente sufren las mujeres y además de las que sufren quienes se autorizan a transgredir el binarismo sexual. Velandia define como trabajadora sexual a:

Quien en el ejercicio de su actividad laboral, en forma más o menos permanente y de manera consciente, oferta su genitalidad o sus habilidades eróticas a otras personas de igual o de diferente sexo, a cambio de una recompensa económica o en prebendas, buscando con ello satisfacer sus necesidades básicas y/o las de su familia, ante la imposibilidad de obtener un empleo. Estas personas no siempre tienen identidad de oficio (tienen una relación con su oficio no distinta de la de cualquier otro trabajador, es decir, no siempre les agrada lo que hacen, valoran como justo el pago que reciben a cambio o lo consideran como una alternativa aceptable o adecuada de subsistencia) ${ }^{29}$.

Dolores Juliano en «Sociología de la sexualidad» plantea que la estigmatización social de la prostitución está vinculada con la construcción de los roles de género y la desconfianza y la agresividad social hacia la sexualidad. A raíz del análisis socio-lingüístico de insultos como «puta» o «hijo de puta», la autora infiere unas herramientas de agresión muy arraigadas para forzar a las mujeres a mantenerse dentro de las normas (sexuales o no). Para esta autora:

La estigmatización puede interpretarse como un distorsionador ideológico que impide captar la imagen real de la persona estigmatizada, en tanto que persona, y que la coloca bajo un rotulo uniformizador en el que sus características más rechazadas socialmente ocupan la totalidad del campo identitario asignado. (...) se interpreta que son prostitutas, con el agravante de que el rótulo de esta actividad a la que se le asigna permanencia esencializada. Se transforma al mismo tiempo (...), en el mayor insulto aplicable ${ }^{30}$.

28. Viveros, Mara. 2004. «El Concepto de género y sus avatares». En Pensar (en) Género. Carmen Millán. et al. (ed.), Bogotá, Ediciones Universidad Javeriana, pp. 171-191.

29. Velandia Mora, Manuel Antonio. Comprensión de la explotación sexual comercial de niños, niñas y adolescentes y de por qué no se denomina trabajo sexual, España, septiembre de 2009. Disponible en: http://es.scribd.com/doc/64015944/

30. JULIANO, Dolores. Excluidas y marginales: una aproximación antropológica, Valencia, Universitat de València, 2004 
Muchas trans dicen que son putas porque la sociedad las obligó, pero yo creo que eso no es verdad, bueno hay «transputas» que fueron obligadas por trata de personas, pero esas son las menos, las demás nos excusamos en el rechazo social para no sentirnos culpables por ser putas, es una manera de disminuir el estigma y el rechazo social porque si eres puta por culpa de los otros eres una víctima, pero una puta que acepta, que optó por putear se convierte en una trabajadora cualquiera, una que trabaja en un trabajo que no es aceptado socialmente. (Betzi, 34 años, cubana)

Yo si tuviera que definirme diría que soy una marica-trans-puta, pero definirme solo es un esfuerzo para la comprensión de los demás, porque yo cada día soy nueva, cada día que vivo actúo, porque la vida es una actuación que nunca se repite, que cada día es nueva, que tiene algo de lo que fui ayer pero que especialmente tiene mucho de lo que quiero ser mañana y además tampoco sé si mañana seguiré siendo puta. (Maribel, 27 años, panameña)

\section{Ni de aquí, ni de allá: migración}

Las trans viven una feminidad, que también es latinoamericana, les cuesta reconocerse en la españolidad trans, porque tendrían que tener una ruptura con su identidad nacional, por ejemplo, ecuatoriana. En sus países de origen son reconocidas como «distintas», pero también en España las reconocen diferentes, lo que dificulta su integración social. Están en un limbo existencial trans, espacial y cultual, se sienten distintas en la medida en que las otras las hacen sentir distintas, pero esa diferencia cultural no es una ganancia, para ellas es una pérdida.

En mi país lo que he visto es la asquerosidad, el dolor, el sufrimiento, las ganas de no volver más, allá si somos la escoria, lo último, lo que no hay, somos la gente sin nombre. Y aquí en tu país, que te podría decir, para nosotros los viajantes, los inmigrantes como nos llamáis, venimos a buscar el dinero para darle de comer a otras familias, porque nuestra vida ya está destruida, somos la basura. (Interlocutora en $2^{\circ}$ Visita a la Zona) ${ }^{31 .}$

Yo decidí venir a España y no a Italia o Alemania, vine a putiar porque aun cuando podía ir a otro país aquí no tenía problemas con el idioma. Yo llegué como turista pero tenía claro que quería quedarme aquí, nunca me había pensado inmigrante yo era una «autónoma indocumentada» y de un momento a otro me di cuenta que me insultaban llamándome inmigrante, lo hizo por primera vez otra puta trans que es española, luego me di cuenta que ser inmigrante era otra forma de exclusión porque los policías tratan diferente a las trans españolas que a las de otras nacionalidades, pero no todas las extranjeras somos inmigrantes, a algunas las discriminan más aun cuando son comunitarias, a las chicas rumanas y algunas de Europa del Este las discriminan mucho más que a las latinas, pero inmigrantes solo somos nosotras,

31. AMARO QUINTAS. Op. cit., p 53. 
las latinas. Es como si nosotras no fuéramos de ninguna parte, no nos quieren ni aquí ni allá. (Bibiana, 38 años, ecuatoriana)

Migrante, racializada, proletaria y trans: la experiencia de articulación de ejes marcadores de la diferencia o de la opresión se vería agudizada por la migración ${ }^{32}$.

Estas son las tecnomáquinas sexuales del siglo XXI: cuerpos vivos a los que se les niega el acceso al espacio político, privados de discurso público y derecho de insumisión, despojados del derecho a sindicamiento, huelga, seguro médico y paro $^{33}$.

Hay ciertos aspectos culturales que por nacionalidad nos hacen diferentes por ejemplo, en el trato con los clientes. Eso también se nota en el trato entre nosotras y en las relaciones que establecemos con la gente en general. (Raquel, 29 años, colombiana)

Hay una xenofobia terrible. Aquí existe racismo más fuerte que en Alemania. Existe que te digan india, muerte de hambre, lárgate a tu país. Maricones sudamericanos de mierda. Yo los botaba en la tierra a todos. (Vanessa, 23 años, ecuatoriana)

\section{Militancia político-sexual}

El logro que más me enorgullezco es de que muchas travestis hemos dejado de ser víctimas pasivas para ser víctimas activas. (...) En una sociedad que te obliga a definirte como hombre o como mujer, es más divertido decir: soy travesti. (...) Lo ideal sería que cada uno pudiera hacer, ser y tener la imagen que quiera. En la medida en que nosotras vamos cambiando, la sociedad va cambiando. Y es porque nosotras nos volvimos sujetas peligrosas. Primero sujetas de conciencia, después sujetas de derecho y sujetas demandantes ${ }^{34}$.

Consideran importante organizarse como colectivo. Ana, de 47 años, ecuatoriana, afirma «Tenemos que abrir una asociación pero de las nuestras, vamos a tener una asociación de mariquitas de la calle. Tengas polla o no, te vistas de mujer o no, trabajes en la calle o no, perteneces a mi organización».

Yo soy travesti y puta y no me siento incluida en las organizaciones LGTB, porque esa «T» no es clara para mí, ni para muchas de nosotras. Las travestis putas somos como una espina en el testículo de cualquier homosexual. Los LGTB dicen representarnos pero nos tienen miedo porque nosotros pasamos de la carreta a la práctica, porque nos decidimos a ser lo que para muchos de los homosexuales es tan solo una fantasía por alcanzar. Muchos

32. GARCía BeCERRA, Op. cit., p 111

33. PRECIADO, Beatriz. Op. cit., p 217.

34. BERKINS, Lohana. Op. cit., sin página.

Feminismo/s 19, junio 2012, pp. 185-209 
homosexuales se dicen gay pero para mí hay una diferencia, el gay es un político sexual y el homosexual es quien no tiene conciencia política de su sexualidad. (Marcela, 27 años, colombiana)

Cuando en las asociaciones hay trans masculinos ellos asumen con las trans y las lesbianas lo peor de ser hombre y lo peor de ser mujer, se olvidan que fueron mujeres y cogen las mañas de los hombres, porque para ser y comportarse como un macho falócrata es suficiente pensarse hombre, no se requiere tener el pene porque ellos mismos y la comunidad en general si los ven calvos, con barba y músculos ya los asumen en el nivel superior de la escala de poder. (Marcela, 27 años, colombiana)

\section{Los derechos humanos son también derechos sexuales}

Los derechos sexuales pueden definirse, en pocas palabras, como aquel conjunto inalienable de derechos que permiten a las personas tomar decisiones libre y autónomamente sobre la sexualidad de cada quien en cualquiera de sus aspectos (emocionales, corporales, sociales, culturales, etc.).

Un derecho es la posibilidad de establecer una pareja legalmente constituida, pero para las trans latinas e indocumentadas este derechos es mucho más lejano. «Una mujer trans no se puede casar con un hombre porque sería matrimonio con alguien del mismo sexo, y no se puede casar con una mujer porque sería con alguien del mismo género. Entonces ¿qué se decide? Se inhibe a esa persona de casarse» ${ }^{35}$.

En las neo-féminas y neo-mujeres al expresar que las características sexuales no coinciden naturalmente con las de las mujeres se evidencia que tanto el cuerpo y el sexo como el género son categorías que se pueden intervenir y modificar, confirmando así la idea de que cuerpo, sexo y género no son estructuras rígidas y al mismo tiempo evidenciando que éstos se construyen, con lo que cuestionan el sistema que naturaliza arbitrariamente atributos y comportamientos. Se confirma así la propuesta de Bourdieu, quien propone que es la experiencia dóxica la que atribuye al mundo una creencia más profunda que todas las creencias, la del sentido común, puesto que ésta no se concibe como creencia ${ }^{36}$. Por lo que se puede concluir que las categorías cuerpo, sexo y género son doxa ${ }^{37}$ y como tal y desde la propuesta conceptual

35. BIMBI, Bruno. Op. cit., sin página.

36. Bourdieu, Pierre. Razones Prácticas, Barcelona, Anagrama, (1994) 1997.

37. Doxa ( $\delta$ ' $\xi \alpha)$ es una palabra griega que se suele traducir por 'opinión'. Fue un concepto utilizado por Parménides, al distinguir la «vía de la verdad» de la «vía de la opinión», y más tarde por Platón. 
de la ontología del lenguaje u ontología constitutiva que propone que el lenguaje es generador de mundos ${ }^{38}$.

\section{A modo de conclusión: una mirada sistémica y constitutiva}

Para Laqueur «Queda entendido que la biología -el cuerpo estable, ahistórico, sexuado- es el fundamento epistemológico de las afirmaciones normativas sobre el orden social» ${ }^{39}$.

Si la ciencia ha alcanzado el lugar hegemónico que ocupa como discurso y como práctica en nuestra cultura, es precisamente gracias a lo que Ian Hacking, Steve Woolgar y Bruno Latour llaman su «autoridad material», es decir, su capacidad para inventar y producir artefactos vivos. Por eso la ciencia en la nueva religión de la modernidad. Porque tiene la capacidad de crear, y no simplemente de describir, la realidad ${ }^{40}$.

Recordemos que desde las epistemologías convencionales o positivistas, se ve el mundo de manera lineal y se asume la identidad aferrada a una voluntad predeterminada y fija. Hoy se sabe que las trayectorias que parecen tan reales son idealizaciones: el mundo reversible no es un caso extraño y particular de la realidad. En un mundo determinista, la irreversibilidad y lo móvil no tendrían sentido, ya que el mundo del mañana estaría contenido en el mundo de hoy. Desde la ciencia no positivista son posibles otras explicaciones, de ahí que sea posible desde epistemologías como la sistémica y desde ontologías como la constitutiva construir otro tipo de aproximaciones que nos posibiliten explicar las vivencias de las neo-féminas y las neo-mujeres desde otras ópticas. A continuación se propone un modelo de análisis que explica la identidad basado en conceptos sistémicos y constitutivos.

El enfoque sistémico entiende al ser humano y a la sociedad como sistemas. Dadas las propiedades de los sistemas vivos los enfoques contextual y situacional son complementarios, interrelacionados, interafectados e interdependientes, pero además, que en la construcción de la identidad el encuentro consigo mismo juega un papel fundamental pues desde éste se construyen las representaciones y se valida el contexto ${ }^{41}$.

Recalcando el concepto de movilidad y la idea de que el ser se construye en la cultura a partir de la dinámica propia de los sistemas, la identidad puede

38. Velandia Mora, Manuel A. Somos seres lingüísticos: aportes desde la Ontología del lenguaje, España, noviembre de 2011. Disponible en: http://es.scribd.com/doc/80084550

39. LAQUeUR, Thomas. Op. cit., p. 33

40. PRECIADO, Beatriz. Op. cit., p. 24

41. Velandia Mora, Manuel Antonio; ÁVILA, Gabriela Luna. Estrategias para la formación en la Convivencia Democrática, Colombia, Pontificia Universidad Javeriana, 2003. 
definirse entonces como: las ideas y las sensación móviles que tiene el ser humano, en una sociedad y tiempo concretos, de ser lo que busca ser con relación a la cultura, a otros seres en su entorno y consigo mismo/a y de seguir siéndolo en el transcurso del tiempo.

Esta definición explicaría que la identidad es por un lado, la emergencia de una construcción, no siempre consciente, que afecta los procesos de socialización del sujeto; y por el otro, que a través de la educación (formal, no formal e informal) se proveen a la personas los referentes de un «deber ser» de la identidad, basados en la cultura, cuya asunción, en alguno casos, hace posible la perpetuación de la cultura, y en otros, la transformación de ésta.

Las personas, especialmente las neo-féminas y las neo-mujeres no viven el «deber ser» en sus procesos de socialización, como tampoco su "querer ser», dado que las representaciones sociales y culturales, además del cruce de miradas (familiares, escolares, eclesiales), afectan su propia construcción y sus procesos de socialización. Como respuesta al acoplamiento estructural con el medio, la persona en sus interrelaciones, se traiciona a sí misma, traiciona su «querer ser» por efecto de la presión social y de acuerdo con sus propias necesidades de hacerse visible o invisible. De la misma manera asumen una identidad que se moviliza de acuerdo con el tipo de relaciones sociales relativas a una cultura y sociedad específicas. La identidad es móvil porque «está siendo» ecosistémica y culturalmente, puede entenderse como la mezcla entre aquello que se espera que sean las personas y lo que ellas mismas desean ser; composición y experiencia a la que se denomina identidad de socialización.

El tránsito identitario se reafirma en la socialización, a partir de la emoción que produce el «reconocimiento» que dichos hechos generan en las demás personas. Aun cuando es evidente que este «reconocimiento» produce exclusión y en algunos casos separación social, escolar y familiar, es, a su vez, un espacio contextual de reafirmación identitaria que transforma al ser en aquello que «quiere ser».

Todo conocimiento es una representación de la realidad, de ahí que la epistemología constructivista plantee que el conocimiento se hace posible al percibir, distinguir y significar la realidad. En el ser humano la cognición opera en tres dimensiones: la persona conoce algo en la medida que lo distingue como algo, lo percibe como algo y lo significa para algo. Ese algo que se conoce, se constituye en la base de la emergencia de otras nuevas percepciones, distinciones y significaciones. Cada persona, por su historia particular, ha venido configurando un sistema cognitivo que la lleva a percibir, distinguir y significar de manera distinta y única, de ahí su necesidad de actuar en congruencia consigo misma y a partir de esa realidad que ha construido para sí. 
Una persona se relaciona con muchas otras y cada una de ellas tiene sus propios dominios explicativos; pudiera afirmarse entonces que hay sobre una persona o un hecho tantos dominios explicativos como personas pretenden explicarla; por tanto, quienes interactúan son generadores de múltiples realidades que se pueden considerar legítimas y necesariamente diferentes por ser particulares. Las identidades sociales de alguien se posibilitan en la construcción de acuerdos o, más concretamente, en la posibilidad de aceptar diferentes realidades y validar distintas explicaciones con respecto a dicha persona.

La realidad y el conocimiento se conciben como un sistema de relaciones. Las distintas realidades se construyen en la medida en que los sistemas observadores distinguen características y elementos en el medio externo, es decir, en tanto diferencian una cosa de otra y crean contrastes y oposiciones en la realidad. En esta perspectiva, la realidad que se percibe y significa es una construcción que se hace a partir de los esquemas propios de distinción que maneja el ser humano como observador y no una entidad objetiva y absoluta que se puede aprehender mediante los sentidos (empirismo) o la razón (racionalismo).

Las neo-féminas y las neo-mujeres no siempre perciben cuándo los estímulos, que son producidos por el medio, potencian en ellas algún cambio estructural y mucho menos se dan cuenta de que se están produciendo dichos cambios.

El ser humano percibe tan sólo aquello para lo que está en posibilidad de hacer distinciones. Lo hace con sus sentidos, al igual que los otros seres vivos, pero distingue usando sus sistemas de percepción teóricos, experienciales y emocionales. Actuar en congruencia con el medio, consigo misma y con la sociedad, no se hace únicamente por medio de procesos racionales, sino también desde lógicas construidas de acuerdo con las historias emocionales.

Si queremos entender el fenómeno del conocimiento, si queremos entender el sistema nervioso, si queremos entender lo que pasa en la convivencia, tenemos que hacernos cargo de este curioso fenómeno: los seres humanos y los seres vivos en general, no podemos distinguir en la experiencia entre lo que llamamos ilusión y percepción como afirmaciones cognitivas sobre la realidad $^{42}$.

Esta aseveración lleva a pensar que, la identidad no es un hecho real sino una ilusión porque al usar el lenguaje para entenderlo, siendo este un generador de mundos, lo que cada quien entiende como identidad propia o la del otro es tan sólo su propio relato cognitivo, o más exactamente, lo que alcanza a

42. Maturana, Humberto. Emociones y lenguaje en educación y política, Bogotá, Dolmen, 1997, p. 49. 
distinguir de lo que el otro o la otra relata de sí. El performance de la actuación cotidiana es también un relato.

La identidad es ilusión, pues si comprendemos que la realidad se construye desde una ontología y sabemos que ésta no necesariamente tiene que ser objetiva, sino que es constitutiva, entonces comprenderemos que el criterio de validez de la realidad del otro o la otra se da a partir de la efectividad que pueda tener para el observador o la observadora y de las condiciones en que dicho observador ve o escucha.

Las identidades sexuales pueden ser de género, de cuerpo, de sexo, de orientación sexual y de Expresiones Comportamentales Sexuales. Como afirma Peter Wade, «las identidades pueden entrar en conflicto, cobran su significado a partir de diversas redes y de su interacción, y los valores que se le atribuyen a una identidad determinada, inciden en la manera como se reclama o se configura dicha identidad» ${ }^{43}$

Las neo-féminas y las neo-mujeres se definen en su identidad a partir de sus dominios explicativos, estos están signados por elementos externos o dominios explicativos de agentes de la autoridad, la ley, las organizaciones sociales, culturales, políticas como también por los demás miembros de la comunidad.

En las redes de intercambio, determinados valores movilizan o niegan la construcción de la identidad. El reconocimiento social de las neo-féminas y las neo-mujeres se manifiesta como agresión, exclusión y separación social o familiar e igualmente en formas de reconocimiento que incrementan, a su vez, su propio auto-reconocimiento identitario

Como lo afirma Wade ${ }^{44}$, la psique de la persona se forma por medio de las identificaciones asumidas desde la infancia, pero, también se establece corporalmente, y el cuerpo se construye en el proceso de formación social. Tal y como se aprecia en el cuerpo de muchas personas, en las neo-féminas y las neo-mujeres los cambios corporales son un signo de la construcción de su identidad y a su vez se convierte en un espacio desde el cual se consolida la estigmatización, la vulneración y la exclusión.

La situación y el entorno en el que las personas se interrelacionan tienen una serie de características que influyen en el tipo de construcciones identitarias que entre todas y cada una producen.

El ser humano es integral, de ahí deriva la importancia en reconocer las variaciones que emergen de sus propiedades como sistema. La persona no

43. Wade, Meter. Op. Cit., p 55

44. Ibid., p 55 
tiene una identidad sino múltiples identidades particulares, sociales y de socialización con relación a su sexo, a su cuerpo, a su género, a su orientación sexual y a sus expresiones comportamentales sexuales.

\section{Referencias bibliográficas}

AGIER, Michel. «La antropología de las identidades en las tensiones contemporáneas», En: Revista Colombiana de Antropología (Instituto colombiano de Antropología) No 36 (enero-diciembre 2000): 6-19. Disponible en: http://www. icanh.gov.co/recursos_user//RCA_Vol_36/v36a01.pdf

Aguiló, Antoni Jesús. Diversidad sexual y derechos humanos: cinco desafios de nuestro tiempo, en Papers de l'ateneu. Número 19, enero 2012. Disponible en: http://ateneuperemascaro.org/documentacio/informes/papers-de-l-ateneunumero-1.html

AmAro QUinTAS. Ángel Manuel. Triplemente vulnerabilizadas. Prostitutas, inmigrantes y transexuales Vulnerabilidad en la salud, servicios de salud y contexto/s, Alicante, Instituto Universitario de Desarrollo Social y Paz, 2010. Disponible en http://www.transexualia.org/DOCUMENTACION/triplemente.pdf

BartolomÉ, Miguel Alberto. En defensa de la etnografía. El Papel contemporáneo de la investigación intercultural, Revista de Antropología Social, diciembre de 2003, pp. 199-222. Disponible en: http://www.ucm.es/BUCM/revistas/ cps/1131558x/articulos/ RASO0303110199A.PDF

BERKINS, Lohana. Travestida para transgredir. Entrevista de Clarisa Palapot. en Socialismo o Barbarie, Año 1 - No 3, Septiembre-Octubre 2000, Buenos Aires, Primera Clase Impresores S.H. Disponible en: http://www.socialismo-o-barbarie.org

BIMBI, Bruno. Entrevista a Mauro Cabral. Los medios hablan de nosotros como personas que necesariamente sufren, en: Revista Imperio G. 6/06/2006. Disponible en: http://bbimbi.blogspot.com/2006/06/revista-imperio-g-entrevista-mauro. html

Bourdieu, Pierre. Razones Prácticas, Barcelona, Anagrama, (1994) 1997.

Bourdieu, Pierre. El Sentido Práctico, Buenos Aires, Siglo XXI, (1980) 2007.

Bourdieu, Pierre. La Dominación Masculina, Barcelona, Anagrama (1998) 2000.

CARdoso Deoliveira, Roberto. O trabalho do antropólogo. São Paulo, Paralelo 15 y Editora Universidade Estadual Paulista. 1998.

ECheverría, Rafael. Ontología del lenguaje. Vol. $3^{\text {a }}$ Ed. Santiago, Chile, Dolmen Ediciones, 1996.

ENGELS, Friedrich. El origen de la familia, de la propiedad privada y del Estado, Ed. Fundamentos, España, 1997, p. 83.

GALTUNG, Johan. Violencia, guerra y su impacto. Sobre los efectos visibles e invisibles de la violencia, Traducción del inglés por María Anabel Cañón, en Zeitschrift 
für interkulturelles Philosophieren, Tübingen, Alemania, polylog. 2004. Disponible en: http://them.polylog.org/5/fgj-es.htm

GARCíA BECERRA, Andrea. Tacones, siliconas, hormonas. Teoría feminista y experiencias trans en Bogotá, Bogotá, Universidad Nacional de Colombia, Facultad de Ciencias Humanas, Escuela de Estudios de Género, 2010

Halberstam, Judith. Masculinidad Femenina, Madrid, Egales, 2008.

JULIANO, Dolores. Excluidas y marginales: una aproximación antropológica, Valencia, Universitat de València, 2004

Laqueur, Thomas. La Construcción del Sexo. Cuerpo y género desde los griegos hasta Freud, Madrid, Cátedra, (1990) 1994.

MATURANA, Humberto. Emociones y lenguaje en educación y política, Bogotá, Dolmen, 1997, p. 49.

Preciado, Beatriz; Halberstan, Judith; Bourcier, Marie Hélène. Retóricas del género/ Políticas de identidad: performance, performatividad y prótesis. Resumen de las sesiones de trabajo. Disponible en: http://www.caladona.org/grups/ uploads/2011/02/retoricas-de-genero-politicas-de-identidad-b-preciado.pdf

PRIGOGINE, Lya. El tiempo y el devenir, Barcelona, Gedisa, 1966.

RuBIN, Gayle. «El tráfico de mujeres: Notas sobre la «economía política» del sexo», en: El género: La construcción cultural de la diferencia sexual. Marta Lamas (comp.), México, PUEG - UNAM, (1975) 1996. pp. 35-96.

StOnE, Sandy. «El imperio contraataca: Un manifiesto postransexual», en: Serias para el debate. No. 3, Lima, Campaña por la convención de los derechos sexuales y los derechos reproductivos, (1991) 2004, pp. 13-32.

Velandia Mora, Manuel A. Los Derechos Humanos También son Sexuales; Los Derechos Sexuales También son Humanos. Alicante, España, MAVM Editorial, 2011. Disponible en: http://es.scribd.com/doc/59477293/

Velandia Mora, Manuel A. Y si el cuerpo grita... Dejémonos de maricadas, Bogotá, Editorial Equiláteros, 1999.

Velandia MorA, Manuel Antonio. «Identidades sexuales móviles: el derecho a estar siendo o la posibilidad emocional, teórica y experiencial de comprender las masculinidades en las minorías sexuales.» Cap. 13 de Saberes, culturas y derechos sexuales en Colombia, editado por Mara Viveros Vigoya, 295-319. Bogotá: Universidad Nacional de Colombia/ Tercer Mundo, 2006

Velandia Mora, Manuel Antonio. Comprensión de la explotación sexual comercial de niños, niñas y adolescentes y de por qué no se denomina trabajo sexual, España, septiembre de 2009. Disponible en: http://es.scribd.com/ doc/64015944/

Velandia Mora, Manuel Antonio. Las identidades móviles de los, las, les seres. Bogotá, Colombia, Vol. 23, Bioética y sexualidad. Colección Bios y Ethos, Universidad del Bosque, El Bosque, 2005, pp. 163-182. 
Velandia Mora, Manuel Antonio; ÁVILA, Gabriela Luna. Estrategias para la formación en la Convivencia Democrática, Colombia, Pontificia Universidad Javeriana, 2003.

Viveros, Mara. 2004. «El Concepto de género y sus avatares». En Pensar (en) Género. Carmen Millán. et al. (ed.), Bogotá, Ediciones Universidad Javeriana, pp. 171-191.

WADE, Meter. «Identidad» en Margarita Rosa Serge de la Ossa, María Cristina Suárez Vargas y Roberto Pineda Camacho, Palabras para desarmar, Bogotá: Ministerio de Cultura, Instituto Colombiano de Antropología e Historia, 2002, pp. 255-264. 